See discussions, stats, and author profiles for this publication at: https://www.researchgate.net/publication/318854065

\title{
Swelling pressure and consolidation of soft clay stabilized with bagasse ash and lime
}

Conference Paper · June 2017

DOI: 10.1201/9781315100333-156

CITATIONS

0

4 authors, including:

\section{Hayder Hasan}

University of Technology Sydney

9 PUBLICATIONS 41 CITATIONS

SEE PROFILE

B. Behzad Fatahi

University of Technology Sydney

183 PUBLICATIONS 1,426 CITATIONS

SEE PROFILE

Some of the authors of this publication are also working on these related projects:

Project Seismic Soil - Foundation - Structure Interaction View project

Numerical modelling of static and dynamic pile load testing by advanced soil models View project
READS

298

Hadi Khabbaz

University of Technology Sydney

176 PUBLICATIONS 1,528 CITATIONS

SEE PROFILE 


\title{
Swelling pressure and consolidation of soft clay stabilized with bagasse ash and lime
}

\author{
Hayder Hasan, Liet Dang, Hadi Khabbaz \& Behzad Fatahi \\ University of Technology Sydney (UTS), Sydney, Australia
}

\begin{abstract}
This study has focused on the effect of using lime (L) from $1.5 \%$ to $6.25 \%$; bagasse ash (BA) between $6 \%$ and $25 \%$ and combination of BA-L reached up to $25 \%$ on the consolidation characteristic of expansive after the swelling pressure has been determined. The results indicated that the swelling pressure was reduced with increasing BA or L. Furthermore, the results were improved when BA was added to soil treated with $\mathrm{L}$. The swelling pressure of untreated soil decreased from $80 \mathrm{kPa}$ (untreated soil) to $7 \mathrm{kPa}$ (treated with 25\% BA-L). In consolidation tests, the pre-consolidation stress has been developed from $180 \mathrm{kPa}$ with untreated soil to $290 \mathrm{kPa}$ with $6.25 \%$ lime and $350 \mathrm{kPa}$ when $18.75 \% \mathrm{BA}$ was added to soil-6.25\% L. Furthermore, better results were ascertained when soft clay stabilized with 25\% BA-L in comparison with compacted virgin soft clay samples. In addition, the compression indices, and swelling indices decreased $97 \%$ and $56 \%$, respectively.
\end{abstract}

\section{INTRODUCTION}

Structures constructed on fine-grained soil can suffer from either soil expansion or consolidation, depending on the structural stresses involved. If the consolidation properties are not kept to acceptable limits, the life of structure may be reduced or the structure may settle significantly. Approximately twenty percent of the total surface soils in Australia may be classified as expansive soil. The construction of road embankment on this type of soil may encounter problems because large settlements can occur under traffic load for a long time. Alternatively, with increasing moisture content heave can happen as a result of soil movements when the swelling pressure is greater than the induced effective stress (Karunarathne et al., 2013). Many infrastructures have to be constructed in poor performing soil close to populated areas due to increasing volume of traffic. Therefore, these soils must be treated before constructing the road structure to achieve the required properties. To control and solve the low strength and stiffness problems, different modification methods are used, such as compaction, chemical stabilization, reinforcement and techniques of reducing pore water pressure. Chemical stabilization of clay with lime is one of the conventional methods that can be used to upgrade the geotechnical properties of expansive soils. Previous researchers disclosed that hydrated lime can effectively enhance the engineering properties of clayey soil by reducing soil consolidation, swelling potential and improving the strength of clayey soil (Amiralian et al., 2012; Kolay and Ramesh, 2016; Ouhadi et al., 2014; Pal and Ghosh, 2013; Salehi and Sivakugan, 2009; Taiyab et al., 2015). The chemical reaction between the particles of clay and lime are divided into two primary forms of enhancement, short term reaction (modification) and long-term reaction (stabilization). The ion exchanges are defined as a short time chemical reaction, which makes the clay minerals be flocculated and agglomerates, hence, a reduction in moisture content, plasticity and swell can follow. The pozzolanic reaction is defined a long time chemical reaction, forming a cementation bond between clay particles, which develops with time of curing.

On the other hand, the advantage of using waste material in ground modification is one of the solutions that facilitate to minimize the cost of the project, either by reducing the use of processed materials such as lime or by increasing the soil bearing capacity. Moreover, this process contributes in reducing the size of landfills and thereby reducing the adverse effects on environment when a waste material has been used in soil stabilization. For that, waste material can be employed to increase the efficiency of lime or cement. Many researchers (Eberemu, 2011; Mir and Sridharan, 2014; Nalbantoglu and Tuncer, 2001; Okoro et al., 2011; Sureban, 2011) have discussed that the benefits of using waste materials. Phanikumar and Sharma (2007) showed that the reduction in swelling might basically be at- 
tributed to replacement of plastic fines of clay by non-plastic fines of fly ash as well as to the flocculation and cementation effects developed with the addition of fly ash. Moreover, the suction would be reduced to fly ash blended expansive clay samples and consequently swelling would be reduced.

Bagasse ash is derived from ignition of sugarcane waste at electrical power stations and is commonly considered as a discarded material. Several studies (Alavéz-Ramírez et al., 2012; Dang et al., 2016; Manikandan and Moganraj, 2014; Osinubi et al., 2009) have been conducted to evaluate the geotechnical properties of soils (e.g. strength, consistency and swell characteristic) of cementitiously stabilised soils. For example, Alavéz-Ramírez et al. (2012) explained that considerable improvement in strength is due to the formation of strong chemical compounds, such as calcium-silicate-hydrates (CSH) and calcium aluminate hydrates $(\mathrm{CAH})$, resulting from the reaction between lime and sugarcane bagasse ash (SCBA), as well as between lime and soil particles. Manikandan and Moganraj (2014) observed that the cationic exchange capacity and coefficient of consolidation for the combination of bagasse ash and hydrated lime significantly decreased when the quantity of bagasse ash was increased with constant lime content. Manikandan and Moganraj (2014) explained the decline due to interlayer swelling type of mineral to the non-interlayer swelling type of soil mineral. According to scanning electron microscopy (SEM) and X-ray diffraction (XRD) analyses conducted by Alavéz-Ramírez et al. (2012), the soil blocks manufactured with $10 \%$ of lime in combination with $10 \%$ of BA exhibited better performance than those samples containing only lime as a stabilizer. (Dang et al., 2016; Osinubi et al., 2009) reported that bagasse ash alone is not suitable for modifying soil California bearing ratio (CBR) properties; however, useful results can be obtained when it is used in combination with lime.

A comprehensive experimental program has been conducted by the authors at the University of Technology Sydney, in order to quantify the physical and geotechnical properties of treated expansive soil using bagasse ash in combination with hydrated lime.

A noticeable increase in the values of UCS and CBR are observed with the addition of Bagasse ash to same soil treated with lime (Hasan et al., 2016). The soil samples used in this study (referred as black soil) were collected from Queensland, Australia. It is intended to demonstrate that the black soil when treated properly can support road construction. The key objective of this paper is to present part of that large array of laboratory tests regarding swelling pressure as well as one dimensional consolidation tests to determine the treated soil consolidation properties.

\section{BACKGROUND}

When soils absorb water, some types of clay have expansion properties which can be determined by three methods according to Sridharan et al. (1986). The free swell test gives the upper bound for the swell limit. The constant volume pressure which has the intermediate value of swelling. In the third method, when the volume of the sample is maintained constant, the swell limit was the smallest value. Soils swell more than others depending on what the soil particles are made of. For example, montmorillonite minerals have a significant capability to attract water so that the swelling may be tremendous and the height may be more than double for such type of clay. The swelling phenomena in unsaturated-expansive clay can be explained once the air occupies a large part of the volume of voids in the soil. According to Briaud (2013), when this type of soil is exposed to water, the voids draw water immediately. Although water enters into the soil mass, air may stay inside the voids. The pressure increases inside the voids until it overcomes the tensile strength of the dry clay. Besides, the pressure creates a series of mini explosion in air bubbles. After that, the trapped air finds a way to escape, and water enters the voids (Briaud, 2013). Many indirect and direct measurements have been developed or modified to evaluate the shrink-swell potential of clayey soils. Indirect methods include the use of soil properties and classification charts to assess the shrink-swell potential. Direct methods include actual measurement of volume change in an oedometer testing apparatus.

The analysis of oedometer tests must take into account the loading and sequence of wetting, surcharge pressure, sample disturbance and apparatus compressibility (Porter and Nelson, 1980). The experimental study that was carried out by (Akcanca and Aytekin, 2012) indicated that the beneficial effect of lime inclusion to control swelling pressures of compacted sand-bentonite mixture specimens were much lower than the swelling pressures of the specimens made of only sand-bentonite mixture. The variation of swelling pressure with developing limestone and hydrated lime contents has been depicted by (Schanz and Elsawy, 2015). They found the swelling pressure value for clay was reduced about the half with addition $10 \%$ limestone and around one sixth when $10 \%$ hydrated lime is added to the clay. The hydrated lime is more effective in reducing swelling pressure of the clay than the limestone because the calcium ion exchange is significantly greater in hydrated lime-clay mixtures than that in limestone-clay mixtures. Schanz and Elsawy (2015) concluded that the reduction of swelling pressures may be due to some chemical reactions that occur when bentonite stabilized by lime are in contact with water. In addition, the swell potential decreases from $34.5 \%$ for pure bentonite to about 5 and $1 \%$ in case 
of soil sample mixed with $5 \%$ and $10 \%$ hydrated lime, respectively. For that, the amount of 5\% lime is considered as an effective treatment of highly expansive clay.

\section{MATERIALS}

The soil sample used in this study was taken from a road construction site in Queensland State in Australia. Based on the Unified Soil Classification System (USCS), the soil symbol is $\mathrm{CH}$ (inorganic clay with high plasticity). Due to the low strength and high compressibility of clayey soil in that region, it is identified as soft clay in this paper. The majority of soft clay deposits in many areas in Queensland is characterized by deep expansive clays susceptible to intense wetting-drying cycles producing surface movements commonly in excess of $130 \mathrm{~mm}$ according to Brandon and Associates consulting engineering (2015). To characterize the soil sample, some geotechnical tests were performed. Soil properties including specific gravity, particle size distribution, standard compaction, evaluation of Atterberg limits, and moisture content test results were obtained by Australian standard methods (AS-2015). Table 1 shows the geotechnical properties of un-treated soil.

Two stabilizing agents have been used in this study, bagasse ash (BA) and lime (L). Bagasse ash is a residue resulting from the burning of sugarcane bagasse in boiler for the production of electrical energy. The weight of bagasse ash, produced from burning one-ton sugarcane bagasse, would be approximately $24 \mathrm{~kg}$. The BA was collected from ISIS Central Sugar Mill located in the Bundaberg Region of Queensland, Australia. The bagasse ash has fallen in water using a ball mill; oven-dried $\left(110^{\circ} \mathrm{C}\right)$ and sieved $(<425 \mu \mathrm{m})$. The value of loss on ignition was $2.9 \%$ in the fractions passing through the $425 \mu \mathrm{m}$ sieve. After drying, BA did not show clumping as well as BA did not have clear consistency limit due to a high concentration of quartz. The hydrated lime is locally purchased from Cement Australia supplier, one of the most widely used construction materials in Australia. BA or/and lime reacts with the soil particles in the presence of water leading to the formation of cementing compounds responsible for the enhancement of engineering properties.

\section{PREPARATION OF SAMPLES AND EXPERIMENTAL PROGRAM}

The soil sample was first air dried, pulverized by a rubber hammer and then passed through a $2.36 \mathrm{~mm}$ sieve. The mixing procedure was carried out in three steps. In the first step, different amounts of pure bagasse ash (BA) $(6 \%, 10 \%, 18 \%$, and $25 \%$ by the dry weight of soil) were added to the prepared soil. Then, hydrated lime (L) with different contents
$(1.5 \%, 2.5 \%, 4.5 \%$, and $6.25 \%$ by the dry weight of soil) were mixed with the soil. Finally, the composite groups of lime- bagasse ash (L-BA) have been achieved at one $\mathrm{L}$ to three $\mathrm{BA}$ ratios as well as the percentage of L-BA was ranging from $6 \%$ to $25 \%$ by the dry weight of natural soil. The hydrated limebagasse ash combi-

Table 1. Properties of soft clay.

\begin{tabular}{ll}
\hline Property & Value \\
\hline USCS classification of the soil & $\mathrm{CH}$ \\
Particle size analysis (\%) & \\
Sand (4.75-0.075 mm) & 18.4 \\
Silt \& Clay $(<0.075)$ & 81.6 \\
Atterberg limits: & \\
Liquid limit (\%) & 86 \\
Plastic limit (\%) & 37 \\
Plasticity index (\%) & 49 \\
Specific gravity & 2.65 \\
Pre-consolidation stress (kPa) & 180 \\
Compression index & 0.433 \\
Swell index & 0.048 \\
\hline
\end{tabular}

nation ratio of $1: 3$, considered as an appropriate combination ratio, was drawn from a number of preliminary unconfined compression strength (UCS) tests conducted on treated soil samples by changing the combination ratio of hydrated lime to bagasse ash after 28 days of curing according to Hasan et al. (2016). After the addition of additives, soil samples were mixed thoroughly in order to obtain a uniform mixture. Soil-additive mixtures were prepared for each soil sample by mixing in the optimum water content, determined based on the standard compaction. Then, a series of swelling pressure and consolidation tests were carried out to establish the influence of the amount of BA or/ and lime on compacted soil-bagasse ash-lime specimens after 7 days of curing.

\subsection{Swelling pressure tests}

The swelling test was performed in accordance with ASTM D4546 (Method C) for measuring the swelling pressure of the specimens. In this study, the load that prevents swell deformation has been measured after the soil sample inundated with water at the oedometer cell. This method can be referred to as a loading-after-wetting test. Besides, the swelling pressure has been used to describe the ability of soil to swell, regarding the pressure required to prevent swelling. In this investigation, the swelling pressure tests were carried out on samples prepared using the standard proctor compaction test at different contents of additives. A standard test is used ring, 50 $\mathrm{mm}$ in diameter and $20 \mathrm{~mm}$ in height. However, the height of sample was $15 \mathrm{~mm}$ (using $5 \mathrm{~mm}$ brass spacer) during the test. The constant height sample technique was used to determine the swell pressure. 
This technique includes to determine the pressure arising from the inhibited swell deformation that develops after saturating the compacted soil sample with water. A proving ring handle was placed above the sample, which was compacted and placed in the system.

\subsection{One-dimensional consolidation tests}

The preparation of the specimen and the testing of 1D consolidation of the bagasse ash - soil, lime soil, and bagasse ash - lime- soil mixes were carried out in accordance with Australian Standard of AS 1289.6.6.1 using a fixed-ring oedometer. After completion of the swelling pressure test under a given vertical load, additional vertical load increments are applied to the specimen in the same manner as in a consolidation test and the load-induced strains were measured. This test was performed in order to determine the magnitude and the rate of volume reduction of soil sample. The load on the specimen was applied through a lever arm, and compression was measured by an LVDT. The specimen was kept under water during the test. Each load was usually kept for 24 hours. All specimens were loaded, unloaded, and reloaded to determine the compression and swell indices.

\section{TEST RESULTS AND DISCUSSION}

\subsection{Swelling pressure results}

Figure 1 compares the effect of bagasse ash (BA), lime (L), and BA-L on the swelling pressure after 7 days of curing. The swelling pressure decreased with increasing BA, L, and BA-L contents, as expected. The reduction in the swelling pressure was significant with BA-L content; the effect of lime was clearer on the swelling pressure than bagasse ash. For example, the swelling pressure was $55 \mathrm{kPa}$ when $1.5 \%$ lime was applied, and it was $75 \mathrm{kPa}$ when $6 \%$ bagasse ash was used. However, the swelling pressure was reduced to $33 \mathrm{kPa}$ with $6 \% \mathrm{BA}-\mathrm{L}$. This reduction may be due to chemical reactions that happen when BA was added to clay mixtures stabilized with lime. Adding BA as a non-expansive material to soft clay could reduce the diffuse double layers because the bagasse ash is primarily composed of spherical noncrystal silicate, aluminum, and iron oxides compounded with some microcrystal material and unburned carbon. Moreover, the lime addition has been reduced water affinity of clayey particles regardless of soil pulverization quality.

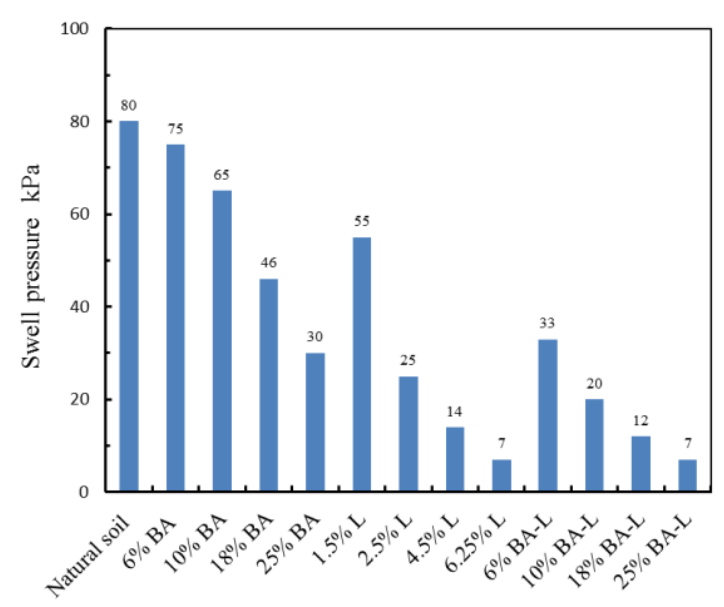

Figure 1. Influence of bagasse ash, lime, and bagasse ash - lime admixture on swelling pressure of the soft clay soil.

\subsection{One-dimensional consolidation results}

Figure 2 indicates the variation of void ratio against the applied effective stress associated with the compacted untreated soil. Referring Figure 2, the values of the pre-consolidation pressure $\left(\sigma_{\sigma}^{z}\right)$ was $180 \mathrm{kPa}$. Moreover, the compression index $\left(C_{c}\right)$ and the swell index $\left(C_{s}\right)$ are approximately 0.433 and 0.048 , respectively.

The empirical $C_{c}$ for remolded clays by (Skempton, 1946) was 0.532 , and $C_{s} / C_{c}$ ratio was ranging between 0.2 to 0.1 (Das and Sobhan, 2013). Although the soil sample was placed more than two days in one-dimensional consolidation device under a constant load, the primary consolidation has not been completed. For this reason, the early stage log time has been used to determine the coefficient of consolidation $\left(c_{\mathrm{v}}\right)$ (Allam and Robinson, 1996). The value of $c_{v}$ was decreased with increasing the level of load. For example, the value of $c_{v}$ at $480 \mathrm{kPa}$ was $0.043 \mathrm{~m}^{2} /$ year and $c_{v}$ at $800 \mathrm{kPa}$ was $0.021 \mathrm{~m}^{2} /$ year. These results were in agreement with the results presented by Robinson and Allam (1996). The coefficient of permeability $(k)$ was determined relying on the theory of Terzaghi after calculating the coefficient of volume change $\left(m_{v}\right)$. The $m_{v}$ was decreased during consolidation as well as the $k$ decreased. For example, $m_{v}$ and $k$ values were $0.215 \mathrm{~m}^{2} / \mathrm{MN}$, $2.89 \times 10^{-12} \mathrm{~m} / \mathrm{sec}$ at $480 \mathrm{kPa}$ whereas the values of $m_{v}$ and $k$ at $800 \mathrm{kPa}$ were $0.161 \mathrm{~m}^{2} / \mathrm{MN}$ and $1.06 \times 10^{-13} \mathrm{~m} / \mathrm{sec}$, respectively. Consolidation results for clay soil specimens stabilized with BA ranging from $6.25 \%$ to $25 \%$, L between $1.5 \%$ and $6.25 \%$, and BA-L up to $25 \%$ cured for 7 days are depicted in Figures 3, 4 and 5. As can be seen in Figure 3, it is clear that the amount of void ratio change decreased with the increase in percentage of BA. The values of the void ratio change were about $0.16,0.16,0.13$ and $0.11 \%$, during application of stresses between 115 $\mathrm{kPa}$ and $690 \mathrm{kPa}$ for the $1.5 \%, 2.5 \%, 4.5 \%$, and $6.25 \%$ lime, respectively, as illustrated in Figure 4. 


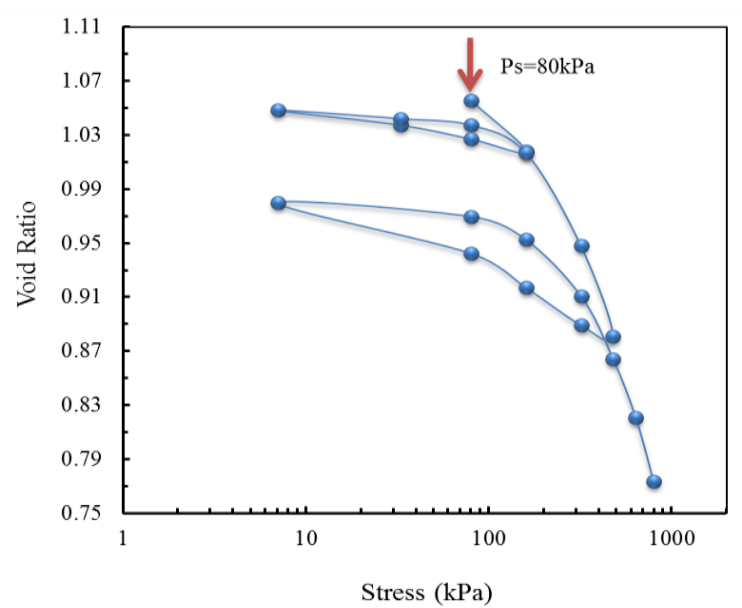

Figure 2. Variation of void ratio with the effective pressure of untreated soil.

In Figure 5, the values of change in void ratio of BA-L soil mixes during loading were $0.15,0.11$, and $0.05 \%$ for 10,18 , and $25 \%$ BA-L, respectively. Overall, it can be noted that samples treated with BA-L had a lower compressibility index, compared to BA and L. This could be related to the fact of superior influence of BA on soil consolidation behavior that may be due to adequate amounts of calcium required for the formation of $\mathrm{CSH}$, which is the major element for strength gain, which forms over the hydration of lime (Manikandan and Moganraj, 2014). Alavéz-Ramírez et al. (2012) reported that significant improvement in strength is due to increased pozzolanic reaction with increased BA treatment, which causes the formation of calcium silicate hydrates, resulting from the reaction between lime and bagasse ash.

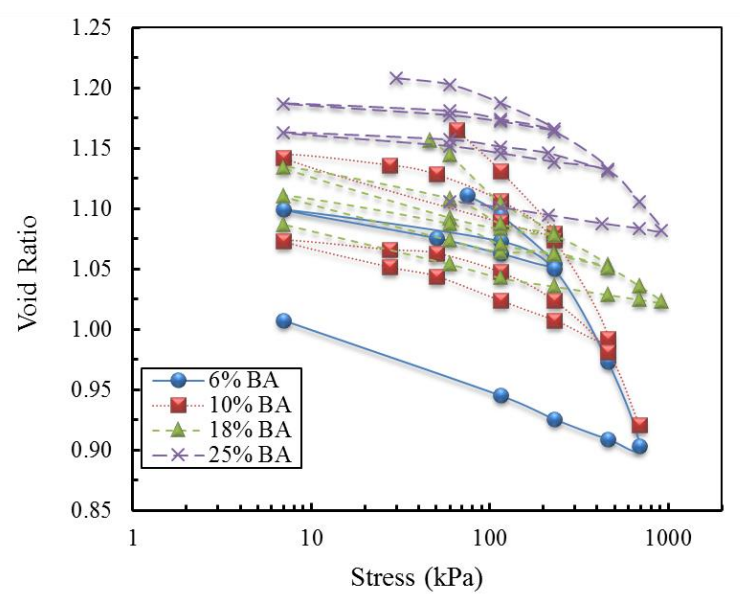

Figure 3. Void ratio versus stress for soil stabilized with different bagasse ash content.

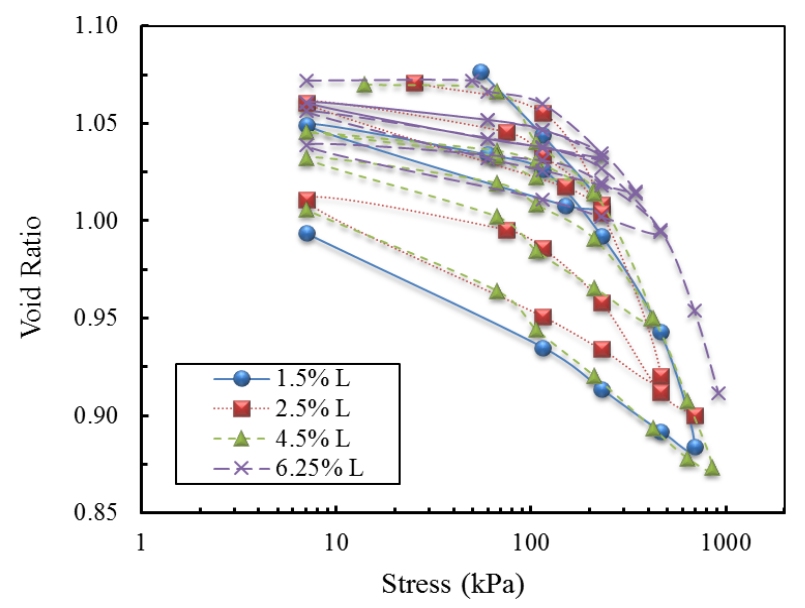

Figure 4. Void ratio versus stress for soil stabilized with different lime content.

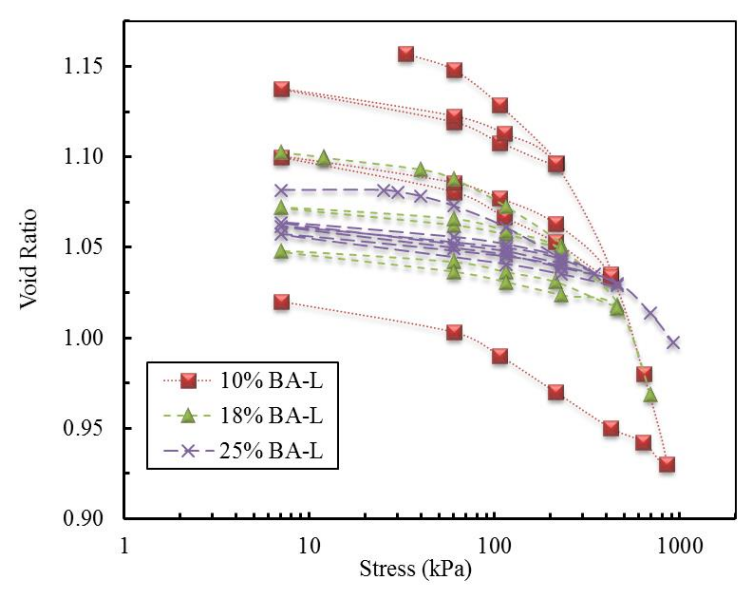

Figure 5. Void ratio versus stress for soil stabilized with different bagasse ash- lime contents.

Figure 6 displays the effect of bagasse ash on preconsolidation pressure was slightly increased. The highest value of $\sigma_{c}^{s}$ was $200 \mathrm{kPa}$ when $\mathrm{BA}$ reached to $25 \%$. On the other hand, the $\sigma_{\sigma}^{*}$ increased from 180 $\mathrm{kPa}$ to $290 \mathrm{kPa}$ when $6.25 \%$ lime was added to the soil. Once, the $25 \%$ BA-L was mixed with soil, the $\sigma_{c}^{s}$ increased to $350 \mathrm{kPa}$. Tables 2 and 3 show the change in compression index and swell index of soil mixed with BA, L and BA-L. The $C_{c}$ value for soil mixed BA-L ranged from 0.3 to 0.01 , whereas the values for BA-soil ranged from 0.35 to 0.2 . Additionally, the $C_{e}$ of L-soil ranged from 0.33 to 0.01 . It can be seen that, the better results ascertained from the mix of $25 \%$ BA-L as compare to of virgin soil strata. For example, the percentage of $C_{e}$ has decreased $97 \%$ and the $C_{s}$ reduced to $56 \%$. 


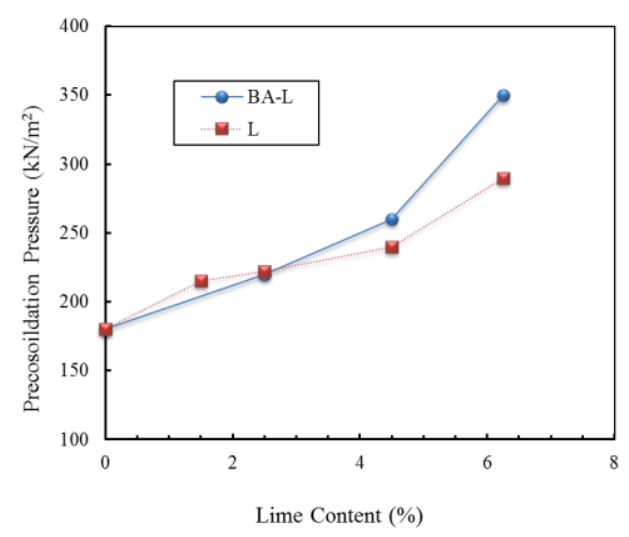

Figures 6. Pre-consolidation pressure versus lime content for soil stabilized with different bagasse ash and lime contents.

Table 2. Summary of compression and swell indices of BA and BA-L stabilized soil.

\begin{tabular}{lllll}
\hline $\begin{array}{l}\text { BA or BA-L } \\
\text { content }(\%)\end{array}$ & \multicolumn{2}{l}{$\begin{array}{l}\text { Soil stabilized } \\
\text { with BA }\end{array}$} & \multicolumn{2}{l}{$\begin{array}{l}\text { Soil stabilized } \\
\text { with BA-L }\end{array}$} \\
\cline { 2 - 5 } & $C_{c}$ & $C_{s}$ & $C_{c}$ & $C_{s}$ \\
\hline 10 & 0.35 & 0.04 & 0.30 & 0.04 \\
18 & 0.23 & 0.04 & 0.04 & 0.03 \\
25 & 0.20 & 0.03 & 0.01 & 0.02 \\
\hline
\end{tabular}

Table 3. Summary of compression and swell indices of L and BA-L stabilized soil.

\begin{tabular}{lllll}
\hline \multirow{2}{*}{$\begin{array}{l}\text { Lime content } \\
(\%)\end{array}$} & \multicolumn{2}{l}{$\begin{array}{l}\text { Soil stabilized } \\
\text { with Lime }\end{array}$} & \multicolumn{2}{l}{$\begin{array}{l}\text { Soil stabilized } \\
\text { with BA -L }\end{array}$} \\
\cline { 2 - 5 } & $C_{\varepsilon}$ & $C_{s}$ & $C_{\varepsilon}$ & $C_{\varepsilon}$ \\
\hline 2.5 & 0.33 & 0.04 & 0.30 & 0.04 \\
4.5 & 0.15 & 0.03 & 0.04 & 0.03 \\
6.25 & 0.10 & 0.02 & 0.01 & 0.02 \\
\hline
\end{tabular}

The variation of coefficient of consolidation for untreated and treated with $18.75 \% \mathrm{BA}-6.25 \% \mathrm{~L}$ and $6.25 \% \mathrm{~L}$ are shown in Figure 7 . It can be observed that the value of $c_{v}$ increases when virgin soil is treated with lime and bagasse ash. The samples with $18.75 \%$ BA- $6.25 \% \mathrm{~L}$ needed less time to reach the end of primary consolidation, resulting from increasing in the coefficient of consolidation. This could be attributed to increase formation of pozzolanic products within the pore spaces of soil from physicochemical changes (Osinubi and Eberemu, 2006). The coefficient of permeability $k$ for soil stabilized with 18. $75 \%$ BA-6.25\% L was $1 \times 10^{-11} \mathrm{~m} / \mathrm{sec}$.

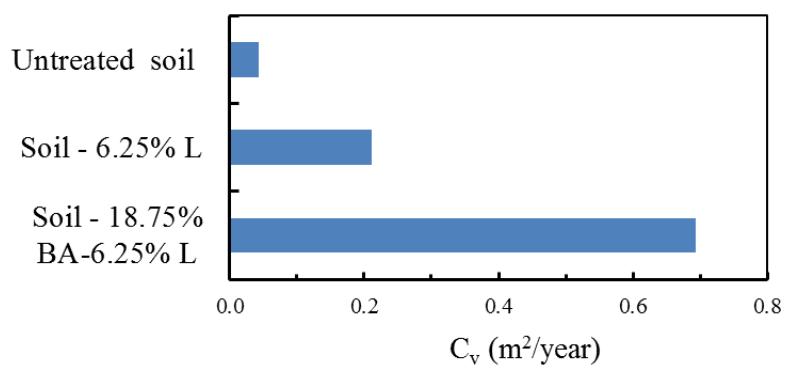

Figures 7. Variation of the coefficient of consolidation for untreated and treated soil samples with different additive contents.

\section{CONCLUSIONS}

Chemical stabilization using bagasse ash and hydrated lime can be an appropriate method to improve the poor characteristic of expansive soil. The main objective of this study was to evaluate the swelling and compressibility behavior of treated soil samples using bagasse ash with or without lime addition. The following concluding remarks are based on the detailed experimental investigation. Addition of up to $25 \%$ admixture, a combined hydrated lime and bagasse ash at a ratio of 1:3 was effective in reducing the swelling pressure, reduction of swelling index, decreasing compressibility indices, and increasing the coefficient of consolidation. The addition of bagasse ash into soft clay treated with lime may change its visible grain size. This is evidenced from an increase in the coefficient of permeability. Adding bagasse ash $(18.75 \%)$ to lime treated soil improved the rate of lime hydration and consequently increased the amount of pre-consolidation pressure up to $21 \%$. This is due to bagasse ash increasing the rate of hydration of lime. The laboratory findings generally highlighted the benefits of employing bagasse ash on improving the swelling and consolidation behavior of lime treated soft soil. Using bagasse ash, a sugarcane waste by-product, in soil stabilization may produce positive outcomes in terms of enhancing lime stabilization process and solving the problems posed by the disposal of bagasse ash.

\section{REFERENCES}

Akcanca, F., \& Aytekin, M. (2012). Effect of wetting-drying cycles on swelling behavior of lime stabilized sandbentonite mixtures. Environmental earth sciences, 66(1), 67-74.

Alavéz-Ramírez, R., Montes-García, P., Martínez-Reyes, J., Altamirano-Juárez, D. C., \& Gochi-Ponce, Y. (2012). The use of sugarcane bagasse ash and lime to improve the durability and mechanical properties of compacted soil 
blocks. Construction and Building Materials, 34, 296-305. doi:10.1016/j.conbuildmat.2012.02.072

Allam, M. M., \& Robinson, R. G. (1996). Determination of coefficient of consolidation from early stage of log $\mathrm{t}$ plot. Geotechnical Testing Journal, Vol. 19, No. 3, pp. 316-320, https://doi.org/10.1520/GTJ10358J. ISSN 0149-6115

Amiralian, S., Chegenizadeh, A., \& Nikraz, H. (2012). Laboratory investigation on the effect of lime on compressibility of soil. The International Conference on Civil and Architectural Applications, Thailand.

Brandon and Associates (2015). Technical factsheet footing on expansive soils. http://www.brandoneng.com/contact.aspx

Briaud, J.-L. (2013). Geotechnical engineering: unsaturated and saturated soils: John Wiley \& Sons.

Dang, L. C., Hasan, H., Fatahi, B., Jones, R., \& Khabbaz, H. (2016). Enhancing the engineering properties of expansive soil using bagasse ash and hydrated lime. International Journal of GEOMATE, 11(25), 2447-2454.

Das, B., \& Sobhan, K. (2013). Principles of geotechnical engineering: Cengage Learning.

Eberemu, A. O. (2011). Consolidation properties of compacted lateritic soil treated with rice husk ash. Geomaterials, 1(03), 70-78.

Hasan, H., Dang, L., Khabbaz, H., Fatahi, B., \& Terzaghi, S. (2016). Remediation of Expansive Soils Using Agricultural Waste Bagasse Ash. Procedia Engineering, 143, 13681375.

Karunarathne, A., Gad, E., Sivanerupan, S., \& Wilson, J. L. (2013). Review of residential footing design on expansive soil in Australia. From book Materials to Structures: Advancement through Innovation. Taylor \& Francis. Pages 575-580. Print ISBN: 978-0-415-63318-5. eBook ISBN: 978-0-203-52001-7. DOI: 10.1201/b15320-101.

Kolay, P., \& Ramesh, K. (2016). Reduction of Expansive Index, Swelling and Compression Behavior of Kaolinite and Bentonite Clay with Sand and Class C Fly Ash. Geotechnical and Geological Engineering, 34(1), 87-101.

Manikandan, A., \& Moganraj, M. (2014). Consolidation and rebound characteristics of expansive soil by using lime and bagasse ash. International Journal of Research in Engineering and Technology, 3(4), 403-411.

Mir, B., \& Sridharan, A. (2014). Volume change behavior of clayey soil-fly ash mixtures. International Journal of Geotechnical Engineering, 8(1), 72-83.

Nalbantoglu, Z., \& Tuncer, E. R. (2001). Compressibility and hydraulic conductivity of a chemically treated expansive clay. Canadian geotechnical journal, 38(1), 154-160.

Okoro, C. C., Vogtman, J., Yousif, A., Agnaou, M., \& Khoury, N. (2011). Consolidation Characteristics of Soils Stabilized with Lime, Coal Combustion Product, and Plastic Waste. Paper presented at the Geo-Frontiers 2011: Advances in Geotechnical Engineering.

Osinubi, K., Bafyau, V., \& Eberemu, A. (2009). Bagasse ash stabilization of lateritic soil Appropriate Technologies for Environmental Protection in the Developing World (pp. 271-280): Springer.

Osinubi, K., \& Eberemu, A. (2006). Effect of bagasse ash on the strength of stabilized lateritic soil. Paper presented at the Proceedings of 5th Nigerian Material Congress, Abuja.

Ouhadi, V., Yong, R., Amiri, M., \& Ouhadi, M. (2014). Pozzolanic consolidation of stabilized soft clays. Applied Clay Science, 95, 111-118.

Pal, S. K., \& Ghosh, A. (2013). Volume change behavior of fly ash-montmorillonite clay mixtures. International Journal of Geomechanics, 14(1), 59-68.
Phanikumar, B., \& Sharma, R. S. (2007). Volume change behavior of fly ash-stabilized clays. Journal of Materials in Civil Engineering, 19(1), 67-74.

Porter, A. A., \& Nelson, J. D. (1980). Strain controlled testing of expansive soils. Paper presented at the Proc. 4th international conference on expansive soils.

Salehi, M., \& Sivakugan, N. (2009). Effects of lime-clay modification on the consolidation behavior of the dredged mud. Journal of waterway, port, coastal, and ocean engineering, 135(6), 251-258.

Schanz, T., \& Elsawy, M. B. (2015). Swelling characteristics and shear strength of highly expansive clay-lime mixtures: A comparative study. Arabian Journal of Geosciences, 8(10), 7919-7927.

Skempton, A. (1946). Notes on the Compressibility of Clays. Quarterly Journal of the Geological Society, 102(1-4), 205209.

Sridharan, A., Rao, A. S., \& Sivapullaiah, P. V. (1986). Swelling pressure of clays. Geotechnical Testing Journal, 9(1), 24-33.

Sureban, V. (2011). Consolidation Characteristics of Fly Ash and Lime Treated Black Cotton Soil. Paper presented at the Proc. of. Int. Conf. on recent Trends in Transportation, Environmental ands Civil Engineering.

Taiyab, M. A., Hossain, M. K., \& Rahman, M. M. (2015). Consolidation Properties of Soft Clay Treated with Different Additives using Surcharge Loading in the Curing Period. DUET, 2(2). 